\title{
Corrigendum to "Repurposing Napabucasin as an Antimicrobial Agent against Oral Streptococcal Biofilms"
}

\author{
Xinyi Kuang $\mathbb{D},{ }^{1}$ Tao Yang $\left(\mathbb{D},{ }^{2}\right.$ Chenzi Zhang, ${ }^{1}$ Xian Peng $\mathbb{D}^{1},{ }^{1}$ Yuan Ju, ${ }^{3}$ Chungen Li, ${ }^{2,3}$ \\ Xuedong Zhou $\mathbb{D}^{1}{ }^{1}$ Youfu Luo $\mathbb{D}^{2},{ }^{2}$ and Xin Xu $\mathbb{D}^{1}$ \\ ${ }^{1}$ State Key Laboratory of Oral Diseases \& National Clinical Research Center for Oral Diseases \& Department of Cariology \\ and Endodontics, West China Hospital of Stomatology, Sichuan University, Chengdu, China \\ ${ }^{2}$ Laboratory of Human Disease and Immunotherapies, West China Hospital, Sichuan University, Chengdu, China \\ ${ }^{3}$ State Key Laboratory of Biotherapy and Cancer Center, West China Hospital, West China Medical School, Sichuan University, \\ Chengdu, China
}

Correspondence should be addressed to Youfu Luo; luo_youfu@scu.edu.cn and Xin Xu; xin.xu@scu.edu.cn

Received 19 November 2021; Accepted 19 November 2021; Published 11 December 2021

Copyright (C) 2021 Xinyi Kuang et al. This is an open access article distributed under the Creative Commons Attribution License, which permits unrestricted use, distribution, and reproduction in any medium, provided the original work is properly cited.

In the article titled "Repurposing Napabucasin as an Antimicrobial Agent against Oral Streptococcal Biofilms" [1], the authors mistakenly generated the line graph of Figure 1(c) using the data from Figure 1(b). The corrected figure is provided as follows. 
<smiles>CC(=O)c1cc2c(o1)C(=O)c1ccccc1C2=O</smiles>

2-acetylfuro-1,4-naphathoquinone

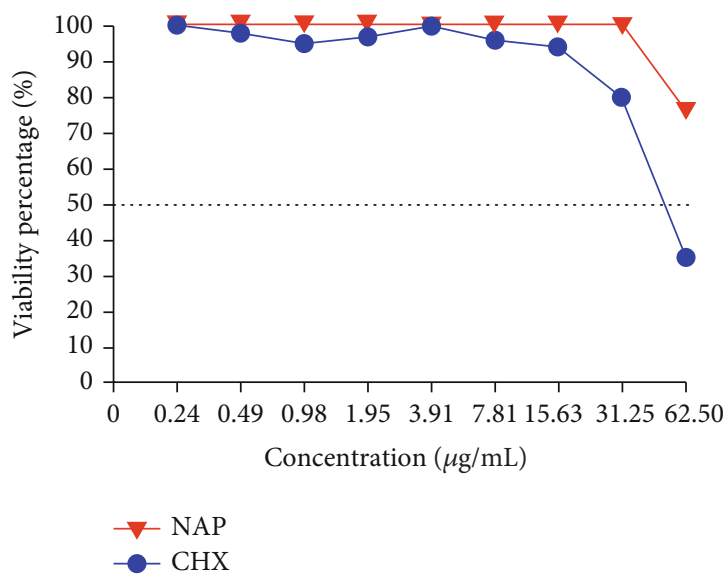

(a)

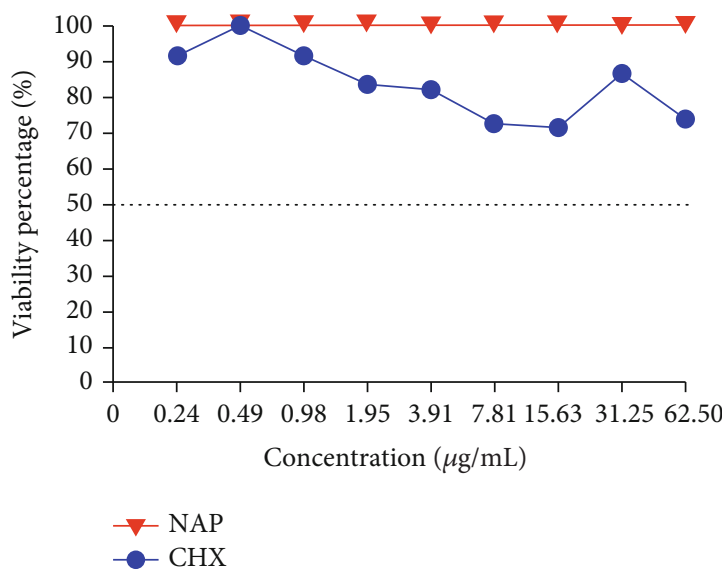

(c) (b)

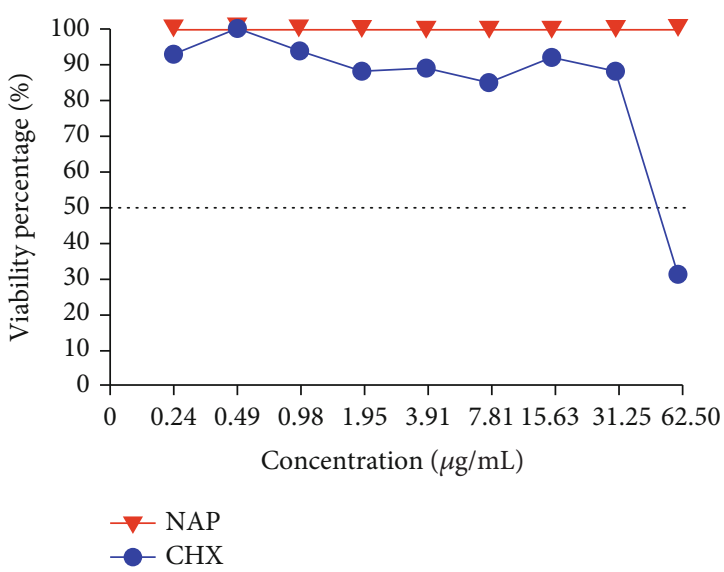

(d)

FIgURE 1: Cytotoxicity of NAP on human oral keratinocytes, human gingival epithelial cells, and macrophages. (a) Chemical structure of

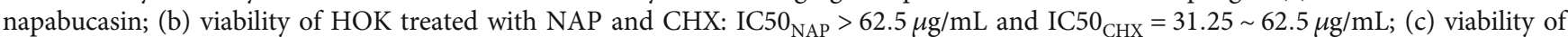
HGE treated with NAP and CHX: IC $50_{\mathrm{NAP}}>62.5 \mu \mathrm{g} / \mathrm{mL}$ and $\mathrm{IC} 50_{\mathrm{CHX}}>62.5 \mu \mathrm{g} / \mathrm{mL}$; (d) viability of RAW264.7 treated with NAP and

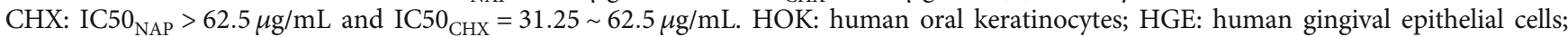
RAW264.7: macrophages RAW264.7.

\section{References}

[1] X. Kuang, T. Yang, C. Zhang et al., "Repurposing napabucasin as an antimicrobial agent against oral streptococcal biofilms," BioMed Research International, vol. 2020, Article ID 8379526, 9 pages, 2020. 